\title{
Impact of Desert Dust Events on the Cardiovascular Disease: A Systematic Review and Meta-Analysis
}

\author{
Alberto Domínguez-Rodríguez ${ }^{1,2,3, *,+}+\mathbb{D}$, Néstor Báez-Ferrer ${ }^{1}{ }^{\mathbb{D}}$, Pedro Abreu-González ${ }^{4}(\mathbb{D})$, Sergio Rodríguez ${ }^{5,6} \mathbb{( D}$, \\ Rocío Díaz ${ }^{7,8}$, Pablo Avanzas $7,8,9$ and Daniel Hernández-Vaquero $7,8,+\mathbb{D}$
}

check for updates

Citation: Domínguez-Rodríguez, A.; Báez-Ferrer, N.; Abreu-González, P.; Rodríguez, S.; Díaz, R.; Avanzas, P.; Hernández-Vaquero, D. Impact of Desert Dust Events on the Cardiovascular Disease: A Systematic Review and Meta-Analysis. J. Clin. Med. 2021, 10, 727. https://doi.org/ $10.3390 /$ jcm 10040727

Academic Editors: Eliano Navarese and Carmine Zoccali

Received: 18 December 2020

Accepted: 5 February 2021

Published: 12 February 2021

Publisher's Note: MDPI stays neutral with regard to jurisdictional claims in published maps and institutional affiliations.

Copyright: (c) 2021 by the authors. Licensee MDPI, Basel, Switzerland. This article is an open access article distributed under the terms and conditions of the Creative Commons Attribution (CC BY) license (https:// creativecommons.org/licenses/by/ $4.0 /)$.
1 Servicio de Cardiología, Hospital Universitario de Canarias, 38010 Tenerife, Spain; nestor.baez@hotmail.com 2 Departamento de Enfermería, Universidad de La Laguna, 38200 Tenerife, Spain CIBER de Enfermedades CardioVasculares (CIBERCV), 28029 Madrid, Spain

4 Departamento de Fisiología, Facultad de Medicina, Universidad de La Laguna, 38200 Tenerife, Spain; pabreugonzalez@gmail.com

5 Estación Experimental de Zonas Áridas, EEZA, CSIC, 04120 Almería, Spain; sergio.rodriguez@csic.es

6 Instituto de Productos Naturales y Agrobiología, IPNA, CSIC, 38206 Tenerife, Spain

7 Área del Corazón, Hospital Universitario Central de Asturias, 33011 Oviedo, Spain; diazmendezro@gmail.com (R.D.); avanzas@gmail.com (P.A.); dhvaquero@gmail.com (D.H.-V.)

8 Instituto de Investigación Sanitaria del Principado de Asturias, 33011 Oviedo, Spain

9 Departamento de Medicina, Universidad de Oviedo, 33003 Asturias, Spain

* Correspondence: adrvdg@hotmail.com; Tel.: +34-922-679040; Fax: +34-922-678460

+ Alberto Domínguez-Rodríguez and Daniel Hernández-Vaquero share first signing author status.

Abstract: Background: Whether or not inhalation of airborne desert dust has adverse health effects is unknown. The present study, based on a systematic review and meta-analysis, was carried out to assess the influence desert dust on cardiovascular mortality, acute coronary syndrome, and heart failure. Methods: A systematic search was made in PubMed and Embase databases for studies published before March 2020. Studies based on daily measurements of desert dust were identified. The meta-analysis evaluated the impact of desert dust on cardiovascular events the same day (lag 0) of the exposure and during several days after the exposure (lags 1 to 5). The combined impact of several days of exposure was also evaluated. The incidence rate ratio (IRR) with $95 \%$ confidence intervals (CI) was calculated using the inverse variance random effects method. Results: Of the 589 identified titles, a total of 15 studies were selected. The impact of desert dust on the incidence of cardiovascular mortality was statistically significant (IRR $=1.018(95 \%$ CI $1.008-1.027) ; p<0.001)$ in lag 0 of the dust episode, in the following day (lag 1) (IRR = 1.005 (95\%CI 1.001-1.009); $p=0.022)$, and during both days combined (lag $0-1)($ IRR $=1.015(95 \% C I 1.003-1.028) ; p=0.014)$. Conclusions: The inhalation to desert dust results in a $2 \%$ increase (for every $10 \mu \mathrm{g} / \mathrm{m}^{3}$ ) in cardiovascular mortality risk.

Keywords: meta-analysis; cardiovascular mortality; acute coronary syndrome; heart failure; particulate matter; dust; desert dust

\section{Introduction}

According to the World Health Organization (Geneva, Switzerland), mitigation of the adverse health effects of exposure to airborne pollutants has become a worldwide health concern [1]. Special attention has focused on pollution related to combustion sources (motor vehicles, industry, biomass burning, etc.), which is composed of a mixture of reactive gases (CO, NOx, and $\mathrm{SO}_{2}$, among others) and particulate matter (PM) (fundamentally hydrocarbons, organic material, soot, sulfate, nitrate, etc.). Exposure to such PM plays a key role in cardiovascular disorders attributed to air pollution [2]. The World Health Organization (Geneva, Switzerland) recommends that the population should not be exposed to concentrations of breathable PM with an aerodynamic diameter $<10 \mu \mathrm{m}$, i.e., $\mathrm{PM}_{10}$, of over $50 \mu \mathrm{g} / \mathrm{m}^{3}$. 
At present, part of the scientific community is investigating the health consequences of the inhalation of airborne desert dust as a component of $\mathrm{PM}_{10}$ breathable particles, which affects over 2000 million people [3]. The main dust-emitting regions are found in the so-called Dust Belt, which extends through North Africa, the Middle East, and Inner Asia (Figure 1) [4].

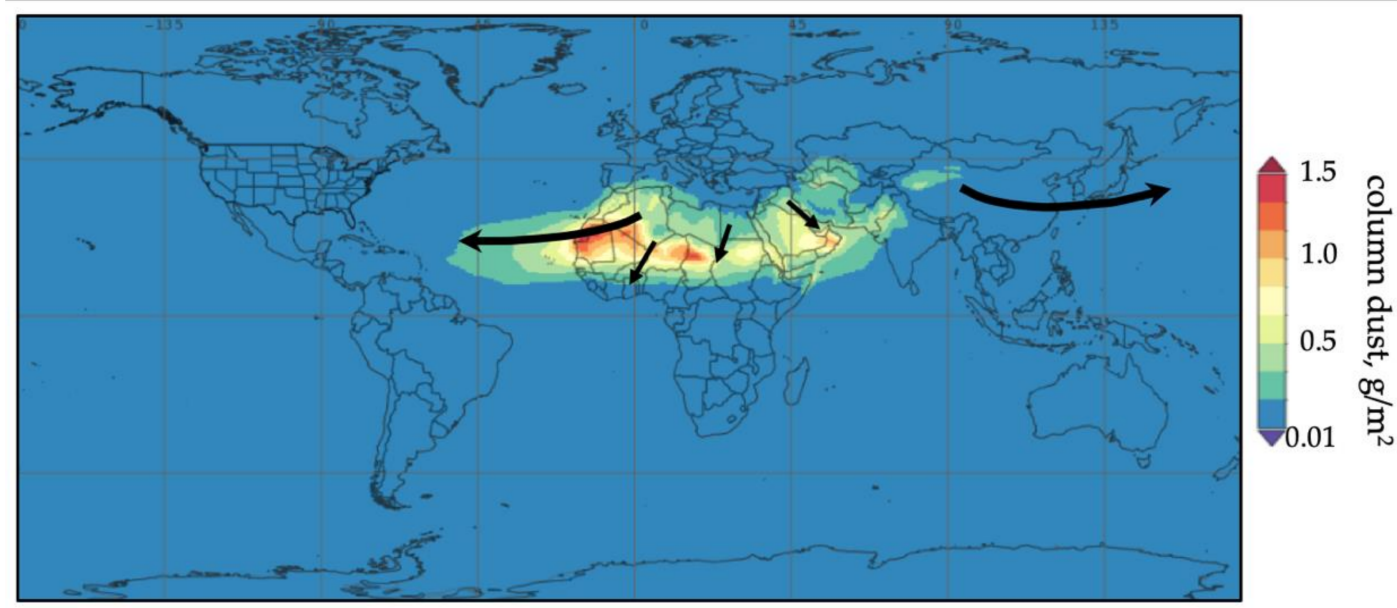

Figure 1. Global mean summer distribution of atmospheric dust according to MERRA-2model. The black arrows indicate the main dust transport routes.

When the dusty air reaches an urban area, the population becomes exposed to the mixture of desert dust and local urban and regional pollution, i.e., $\mathrm{PM}_{10}$ is the sum of $\mathrm{PM}_{10}$-dust $+\mathrm{PM}_{10^{-}}$ non-dust (particles generated by industry, motor vehicles, combustion, etc.) [5-8]. When North African dust reaches southern Europe, $\mathrm{PM}_{10}$-dust is usually present in concentrations of between $10-60 \mu \mathrm{g} / \mathrm{m}^{3}$ and represents $25-50 \%$ of $\mathrm{PM}_{10}$ [6]. However, in North Africa and the Middle East, the $\mathrm{PM}_{10}$-dust concentrations can exceed $1000 \mu \mathrm{g} / \mathrm{m}^{3}$ and represent $>99 \%$ of $\mathrm{PM}_{10}$ [9].

Many studies have been conducted in different parts of the world analyzing the possible impact of desert dust on health. However, the available evidence is not fully conclusive. Whereas some studies have reported a small yet significant influence, others have found no impact $[3,10-12]$. The statistical power of time series studies that analyze the influence of dust on health is a very common and underestimated problem. Simulations underscore that a time series study with an inclusion period of four years and an average of 22 events a day would have a statistical power of only $52 \%$ [13]. In this scenario, the absence of a statistically significant association in such research studies does not mean that there is no association [14]. For this reason, an analysis is needed comprising a large number of events and which allows us to know the real epidemiological association between desert dust and cardiovascular events. The present study, based on a systematic review and meta-analysis, was carried out to assess the influence of exposure to desert dust on the incidence of cardiovascular mortality, acute coronary syndrome (ACS), and heart failure.

\section{Materials and Methods}

The protocol was registered on PROSPERO (CRD42020181532). We conducted and report this systematic review in accordance with the Preferred Reporting Items for Systematic Reviews and Meta-analyses statement [15]. Our research was carried out according to The Code of Ethics of the World Medical Association, Ferney-Voltaire, France, (Declaration of Helsinki). Patient consent was not required.

\subsection{Search Strategy and Selection of Studies}

A systematic search was made of the PubMed and Embase databases for articles published until March 2020, with the purpose of identifying observational studies including 
any human population residing in urban or rural areas exposed to desert dust. The search made use of free text and keywords, considering different definitions related to desert dust, sandstorms, and cardiovascular events. The full search strategy is described in the Supplementary Materials Figure S1.

\subsection{Definition of Exposure to Desert Dust and Study Selection Criteria}

We selected studies in which desert dust (tracked in terms of increases in $\mathrm{PM}_{10}$ due to desert dust blowing in ambient air [1,16]) was characterized. The inclusion criteria were:

- Comparison of exposure to desert dust versus no such exposure.

- Description of the influence of desert dust (per unit increase) on the incidence of cardiovascular mortality, ACS, or heart failure.

- Identification of the exposure of desert dust in the breathable fraction of the particulate material $\mathrm{PM}_{10}[16]$.

- Human studies.

- Studies with a methodologically adequate design. In other words, studies controlling the main confounding factors (meteorological variables and pollutants in gaseous phase) and comprising time series or adopting a cross-case design [17].

- Studies in Spanish or English.

Some Asian studies used total PM as proxy of inhalable dust concentration. A significant difference of this proxy to dust in $\mathrm{PM}_{10}$ is not expected due to super-coarse particles (larger than 10 microns) tend to experience quick dry deposition during the transport across Asia.

\subsection{Objectives}

The objective of this study was to evaluate the impact of desert dust on 3 types of cardiovascular events: Cardiovascular mortality, ACS, and heart failure. For this purpose, we examined whether the dust episodes were associated to the cardiovascular event on the same day as the dust episode (lag 0 ) or whether there was a lag of 1, 2, 3, 4, or 5 days in the cardiovascular event with respect to the dust episode (i.e., lag 1, lag 2, lag 3, lag 4, or lag 5 , respectively). The combined impact of several days of exposure was also evaluated 0-1 days (lag $0-1), 2-5$ days (lag 2-5), and 0-5 days (lag 0-5) after the dust episode.

\subsection{Data Extraction and Evaluation of the Quality of the Studies}

Three members of the team (A.D.-R., N.B.-F., and P.A.-G.) independently examined the title and abstract of the articles, selecting those publications that met the inclusion criteria. Two other members (S.R. and R.D.) evaluated the previously selected full-text articles and decided their final inclusion on an independent basis. Disagreements were resolved through debate among all the team members. The mentioned evaluating members were blinded to the names of the authors, the institutions, and the names of the journals. Another 3 investigators (A.D.-R., P.A., and D.H.-V.) used the Cochrane ROBINS scale to evaluate the quality of the observational studies [18].

The data extracted from the selected studies were entered in an Excel spreadsheet. If a given study presented various cardiovascular events (cardiovascular mortality, ACS, or heart failure), each result was registered individually. Likewise, if a given study reported several estimated effects (different lags) for each cardiovascular event, these were also compiled. Data extraction included details on citations (first author, title, journal, and date of publication), study design and statistical analysis, place of study (region/country), study period, outcome assessment (cardiovascular mortality, ACS, or heart failure), confounding variables, number of events and estimated effect based on the odds ratio, relative risk, or incidence rate ratio (IRR).

\subsection{Statistical Analysis}

For each objective, we conducted a meta-analysis using the inverse variance random effects method. Heterogeneity was assessed by calculating $\mathrm{I}^{2}$. In this regard, $\mathrm{I}^{2}<50 \%$ 
indicates low heterogeneity, $50-75 \%$ moderate heterogeneity, and $>75 \%$ great heterogeneity [19]. As established by protocol, the detection of great heterogeneity implied that the meta-analysis or weighted mean could be biased, and consequently, that no absolute certainty could be concluded. In such cases, the causes of this great heterogeneity were analyzed. The Begg and Egger tests were used to evaluate publication bias. Due to the risk of multiple comparisons, the results of the secondary objectives were considered exclusively exploratory or generators of hypotheses. The analyses were repeated to study the influence of desert dust with each day of $\operatorname{lag}(\operatorname{lag} 1, \operatorname{lag} 2, \operatorname{lag} 3, \operatorname{lag} 4$, and $\operatorname{lag} 5)$ after the dust episode. A weighted mean was considered to be meaningless when there were fewer than 3 articles for analysis. For this study, the results provided by the articles in the form of odds ratio, relative risk, or IRR were analyzed jointly, and the weighted mean was given as IRR with the corresponding 95\% confidence interval (95\% CI). The result was provided based on increments of $10 \mu \mathrm{g} / \mathrm{m}^{3}$ of $\mathrm{PM}_{10}$-dust, and a statistically significant association was considered to be present for $p<0.05$. All the statistical analyses were carried out using the STATAIC 15.1 package (StataCorp, College Station, Lakeway, TX, USA).

\section{Results}

\subsection{Systematic Selection of Studies}

Figure 2 shows the study flowchart according to the PRISMA criteria. A total of 589 articles were identified, of which 513 were excluded and 76 were subjected to review. Of these publications, 61 were excluded, and only 15 were found to meet all the inclusion criteria for evaluating the impact of desert dust on the incidence of cardiovascular mortality, ACS, and heart failure. The selected studies are shown in Table 1.

\subsection{Cardiovascular Mortality}

Of the selected studies, 8 evaluated the impact of $\mathrm{PM}_{10}$-dust during desert dust episodes on cardiovascular mortality [20-27], comprising a total of 477,771 events. For day-lag 0 of the event, the impact was IRR $=1.018$ (95\% CI 1.008-1.027); $p<0.001$, which represents almost a $2 \%$ daily increase in cardiovascular mortality for every $10 \mu \mathrm{g} / \mathrm{m}^{3}$ increase in $\mathrm{PM}_{10}$-dust; $\mathrm{I}^{2}=49.54 \%$ (Figure 3). The Begg and Egger tests yielded $p=0.71$ and $p=0.14$, respectively.

For lag 1, the impact of $\mathrm{PM}_{10}$-dust was IRR $=1.005$ (95\% CI 1.001-1.009); $p=0.022$; $\mathrm{I}^{2}=34.59 \%$. The Begg and Egger tests yielded $p=1$ and $p=0.44$, respectively. Lastly, regarding the combined effects of exposure on the same day of the event and one day later (lag $0-1)$, the impact of $\mathrm{PM}_{10}$-dust was IRR $=1.015(95 \%$ CI $1.003-1.028) ; p=0.014 ; \mathrm{I}^{2}=0 \%$. The Begg and Egger tests yielded $p=0.31$ and $p=0.33$, respectively (Table 2).

For lag 2 in relation to cardiovascular mortality, the impact of $\mathrm{PM}_{10}$-dust was IRR $=1.003$ (95\%CI 1-1.005); $p=0.04 ; \mathrm{I}^{2}=3.34 \%$. The Begg and Egger tests yielded $p=0.46$ and $p=0.52$, respectively. For lag $0-5$ in relation to cardiovascular mortality, the impact of $\mathrm{PM}_{10}$-dust was $\mathrm{IRR}=1.023$ (95\%CI 0.999-1.047); $p=0.053 ; \mathrm{I}^{2}=0 \%$. The Begg and Egger tests yielded $p=0.73$ and $p=0.88$, respectively (Table 2). Fewer than three studies contributed information on the influence of $\mathrm{PM}_{10}$-dust in relation to lag 3, lag 4, lag 5, and lag 2-5. Therefore, no weighted means were calculated for these days. 


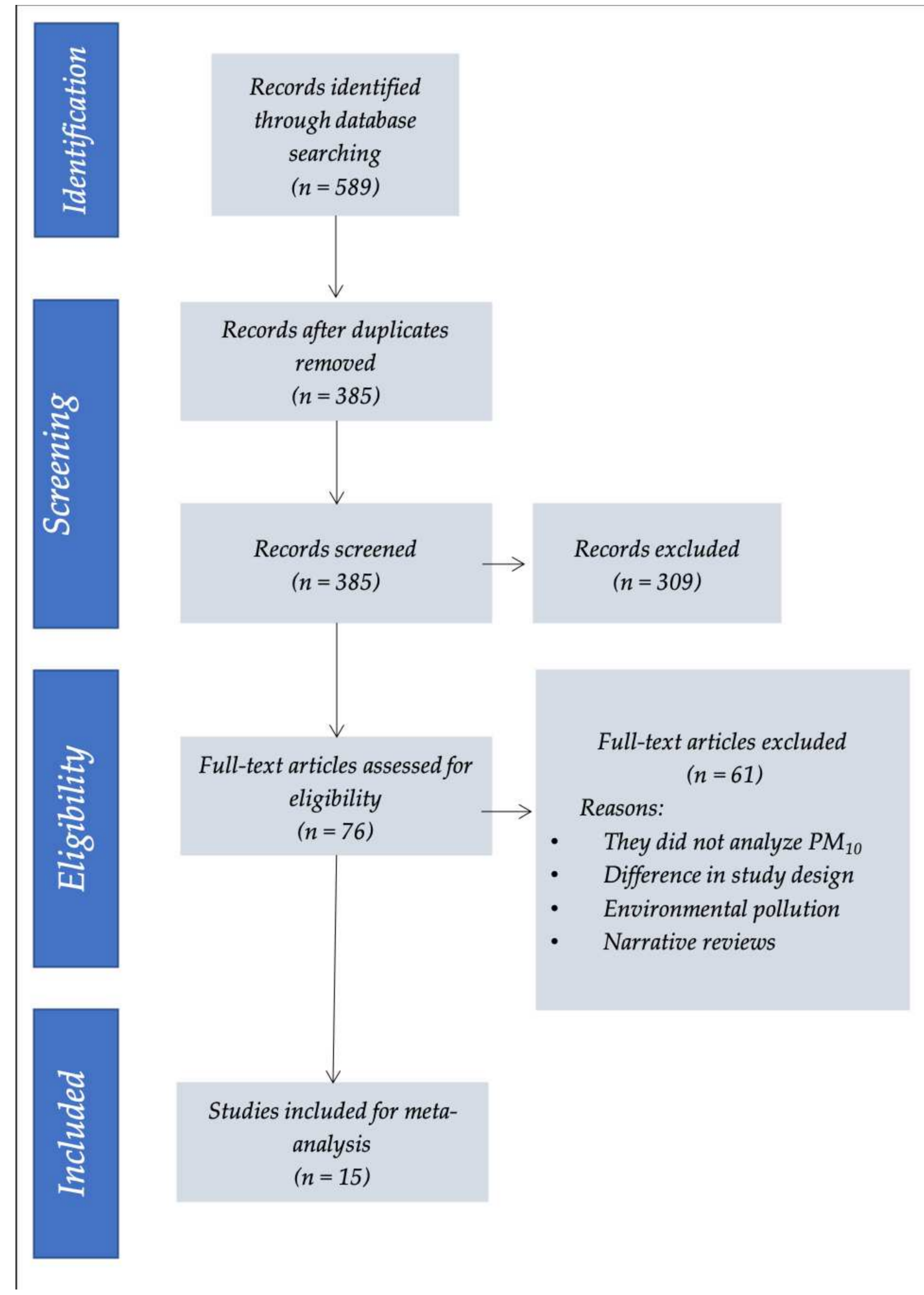

Figure 2. Selection of studies (PRISMA criteria). 


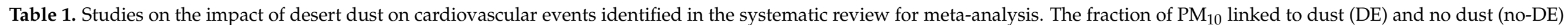
event is shown.

\begin{tabular}{|c|c|c|c|c|c|c|c|c|c|}
\hline Authors & Region & Country & Design & $\mathrm{CE}$ & $\begin{array}{c}\mathrm{PM}_{10} \\
\mathrm{DE}\end{array}$ & $\begin{array}{c}\mathrm{PM}_{10} \\
\text { no-DE }\end{array}$ & $\mathbf{R}$ & Period & Risk of Bias \\
\hline Zauli, 2011 [20] & Emilia Romagna & Italy & $\mathrm{CC}$ & $\mathrm{CM}$ & 38 & 42 & 0.9 & $2002-2006$ & Low \\
\hline Samoli, 2011 [21] & Athens & Greece & TS & $\mathrm{CM}$ & 47 & 39 & 1.2 & 2001-2006 & Low \\
\hline Malone, 2011 [22] & Rome & Italy & $\mathrm{CC}$ & $\mathrm{CM}$ & 52 & 37 & 1.4 & 2001-2004 & Low \\
\hline Perez, 2012 [23] & Barcelona & Spain & TS & $\mathrm{CM}$ & 39 & NS & & 2003-2007 & Moderate \\
\hline Kashima, 2012 [24] & 5 cities & Japan & TS & $\mathrm{CM} / \mathrm{ACS}$ & 184 & 22 & 8.3 & 2005-2010 & Low \\
\hline Tam, 2012 [25] & Hong Kong & China & $\mathrm{CC}$ & $\mathrm{CM} / \mathrm{ACS} / \mathrm{HF}$ & 134 & 50 & 2.7 & 1998-2002 & Low \\
\hline Neophytou, 2013 [26] & Nicosia & Cyprus & TS & $\mathrm{CM}$ & 116 & 53 & 2.2 & 2004-2007 & Low \\
\hline Shahsavani, 2020 [27] & Tehran & Iran & $\mathrm{CC}$ & $\mathrm{CM}$ & 192 & 82 & 2.3 & 2015-2017 & Low \\
\hline Dominguez-Rodriguez, 2020 [14] & Tenerife & Spain & $\mathrm{CC}$ & ACS & 92 & 16 & 5.6 & 2014-2017 & Low \\
\hline Vodonos, 2015 [28] & Béer-Sheva & Israel & $\mathrm{CC}$ & ACS & 2650 & 50 & 53 & 2001-2010 & Low \\
\hline Vaduganathan, 2016 [29] & Brescia & Italy & TS & $\mathrm{ACS} / \mathrm{HF}$ & NS & NS & & 2004-2007 & Moderate \\
\hline $\mathrm{Al}, 2018[30]$ & Gaziantep & Turkey & TS & $\mathrm{ACS} / \mathrm{HF}$ & 74 & 72 & 1.0 & 2009-2014 & Low \\
\hline Zhang, 2016 [31] & Beijing & China & $\mathrm{CC}$ & ACS & NS & NS & & 2014-2014 & Moderate \\
\hline Matsukawa, 2014 [32] & Fukuoka & Japan & $\mathrm{CC}$ & ACS & 55 & 29 & 1.9 & 2003-2010 & Low \\
\hline Yang, 2009 [33] & Taipei & Taiwan & $\mathrm{CC}$ & CI & 112 & 55 & 2.0 & 1996-2001 & Low \\
\hline
\end{tabular}

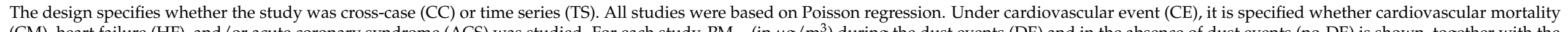

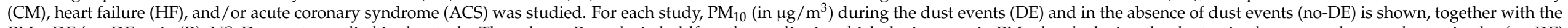

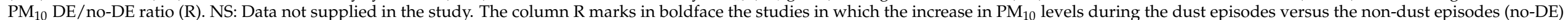

proved relevant $(R \geq 2)$. 


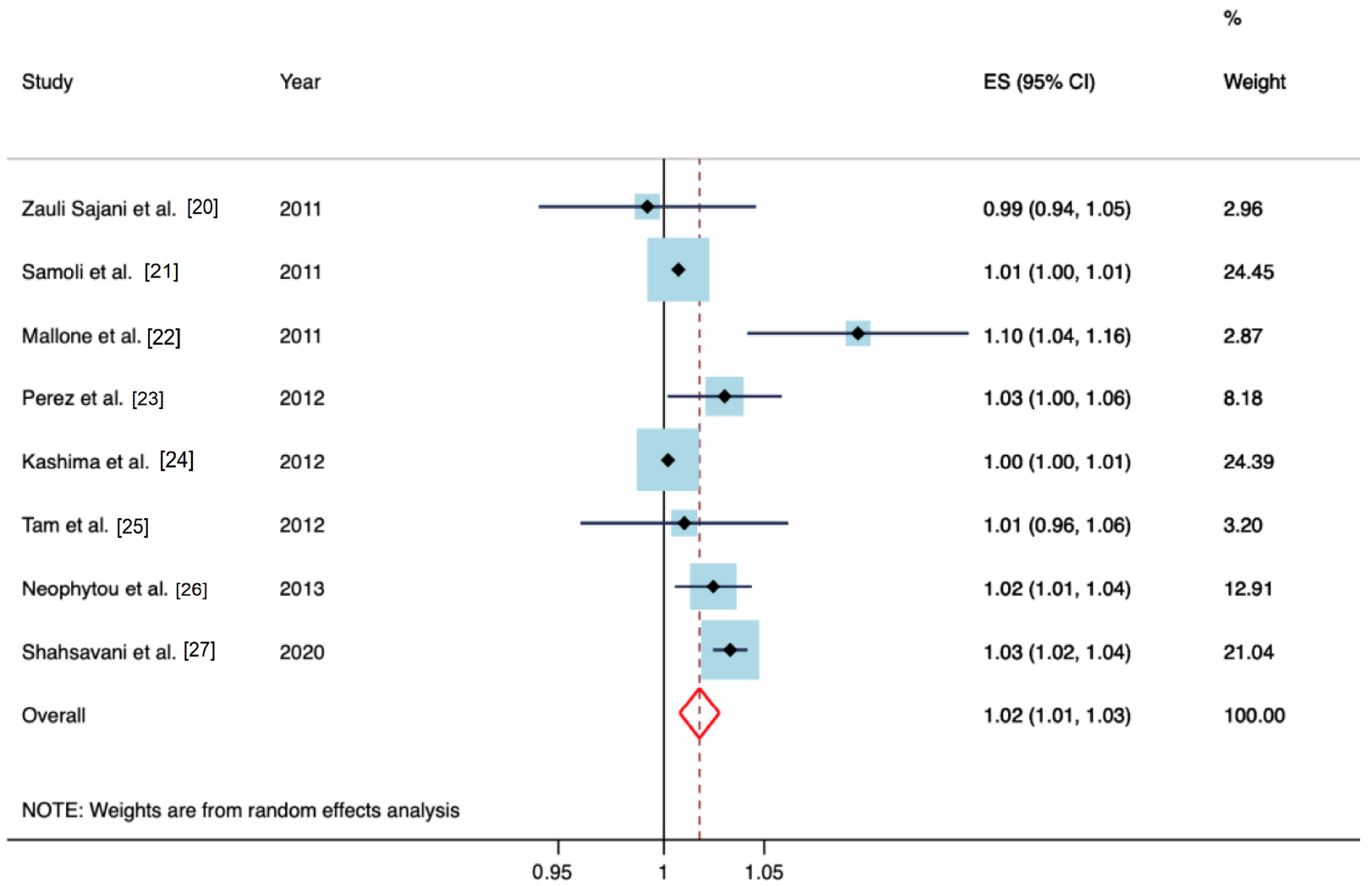

Figure 3. Meta-analysis (forest plot) of the influence of desert dust on cardiovascular mortality (lag $0=$ on the same day). IRR: Incidence rate ratio.

Table 2. Influence of desert dust on cardiovascular mortality, acute coronary syndrome and heart failure for the different lag days. Lag 0 = same day; lag $1=\operatorname{lag}$ of one day; lag $2=\operatorname{lag}$ of 2 days; lag $3=\operatorname{lag}$ of 3 days; $\operatorname{lag} 4=\operatorname{lag}$ of 4 days; lag $0-1=\operatorname{lag}$ of $0-1$ day; lag $0-5=$ lag of $0-5$ days.

\begin{tabular}{|c|c|c|c|c|c|}
\hline Objective & Incidence Rate Ratio & $p$-Value & $I^{2}$ & $\begin{array}{c}\text { Egger } \\
(p \text {-Value })\end{array}$ & $\underset{\text { ( } p \text {-Value) }}{\text { Begg }}$ \\
\hline \multicolumn{6}{|c|}{ Cardiovascular mortality } \\
\hline Lag 0 & 1.018 (95\%CI 1.008-1.027) & $<0.001$ & $49.54 \%$ & 0.14 & 0.71 \\
\hline Lag 1 & 1.005 (95\%CI 1.001-1.009) & 0.022 & $34.59 \%$ & 0.44 & 1.00 \\
\hline Lag 2 & 1.003 (95\%CI $1.000-1.005)$ & 0.040 & $3.34 \%$ & 0.52 & 0.46 \\
\hline Lag 0-1 & $1.015(95 \%$ CI $1.003-1.028)$ & 0.014 & $0.00 \%$ & 0.33 & 0.31 \\
\hline Lag $0-5$ & 1.023 (95\%CI $0.999-1.047)$ & 0.053 & $0.00 \%$ & 0.88 & 0.73 \\
\hline \multicolumn{6}{|c|}{ Acute coronary syndrome } \\
\hline Lag 0 & 1.002 (95\%CI 0.999-1.004) & 0.144 & $0.00 \%$ & 0.11 & 0.67 \\
\hline Lag 1 & 1.004 (95\%CI 0.999-1.009) & 0.071 & $13.39 \%$ & 0.13 & 0.22 \\
\hline Lag 2 & 1.001 (95\%CI $0.998-1.005)$ & 0.449 & $15.62 \%$ & 0.59 & 0.22 \\
\hline Lag 3 & 0.986 (95\%CI 0.949-1.028) & 0.507 & $6.24 \%$ & 0.14 & 0.60 \\
\hline Lag 4 & 1.025 (95\%CI $0.902-1.164)$ & 0.706 & $43.07 \%$ & 0.34 & 0.29 \\
\hline Lag 0-1 & $1.003(95 \%$ CI $1.001-1.006)$ & 0.006 & $0.00 \%$ & 0.46 & 0.73 \\
\hline \multicolumn{6}{|l|}{ Heart failure } \\
\hline Lag 0 & 1.001 (95\%CI 0.996-1.006) & 0.670 & $0.00 \%$ & 0.94 & 0.74 \\
\hline Lag 1 & $1.033(95 \%$ CI $0.977-1.091)$ & 0.253 & $0.00 \%$ & 0.06 & 0.29 \\
\hline Lag 2 & $1.004(95 \%$ CI $0.984-1.024)$ & 0.698 & $0.00 \%$ & 0.71 & 0.30 \\
\hline
\end{tabular}

\subsection{ACS}

Of the selected studies, only 8 provided information on the impact of $\mathrm{PM}_{10}$-dust on the incidence of ACS $[14,24,25,28-32]$, comprising a total of 128,633 events. For lag 0 in 
relation to ACS, the impact of $\mathrm{PM}_{10}$-dust was IRR $=1.002$ (95\% CI 0.999-1.004); $p=0.144$; $\mathrm{I}^{2}=0 \%$. The Begg and Egger tests yielded $p=0.67$ and $p=0.11$, respectively. For lag 1 in relation to ACS, the impact of $\mathrm{PM}_{10}$-dust was IRR $=1.004$ (95\% CI 0.999-1.009); $p=0.071$; $\mathrm{I}^{2}=13.39 \%$. The Begg and Egger tests yielded $p=0.22$ and $p=0.13$, respectively. For lag 2 in relation to ACS, the impact of $\mathrm{PM}_{10}$-dust was IRR $=1.001$ (95\% CI 0.998-1.005); $p=0.449$; $\mathrm{I}^{2}=15.62 \%$. The Begg and Egger tests yielded $p=0.22$ and $p=0.59$, respectively. For lag $0-1$ in relation to ACS, the impact of $\mathrm{PM}_{10}$-dust was IRR $=1.003$ (95\% CI 1.001-1.006); $p=0.006 ; \mathrm{I}^{2}=0 \%$. The Begg and Egger tests yielded $p=0.73$ and $p=0.46$, respectively. All the meta-analyses performed for different days can be seen in Table 2. Fewer than three studies reported information on the influence of $\mathrm{PM}_{10}$-dust in relation to lag 3, lag 4, lag 5, and lag 2-5. Therefore, no weighted means were calculated for these days.

Figure 4 graphically displays the impact of $\mathrm{PM}_{10}$-dust in relation to lag 0 , lag 1 , and lag 2 for the different cardiovascular events studied.
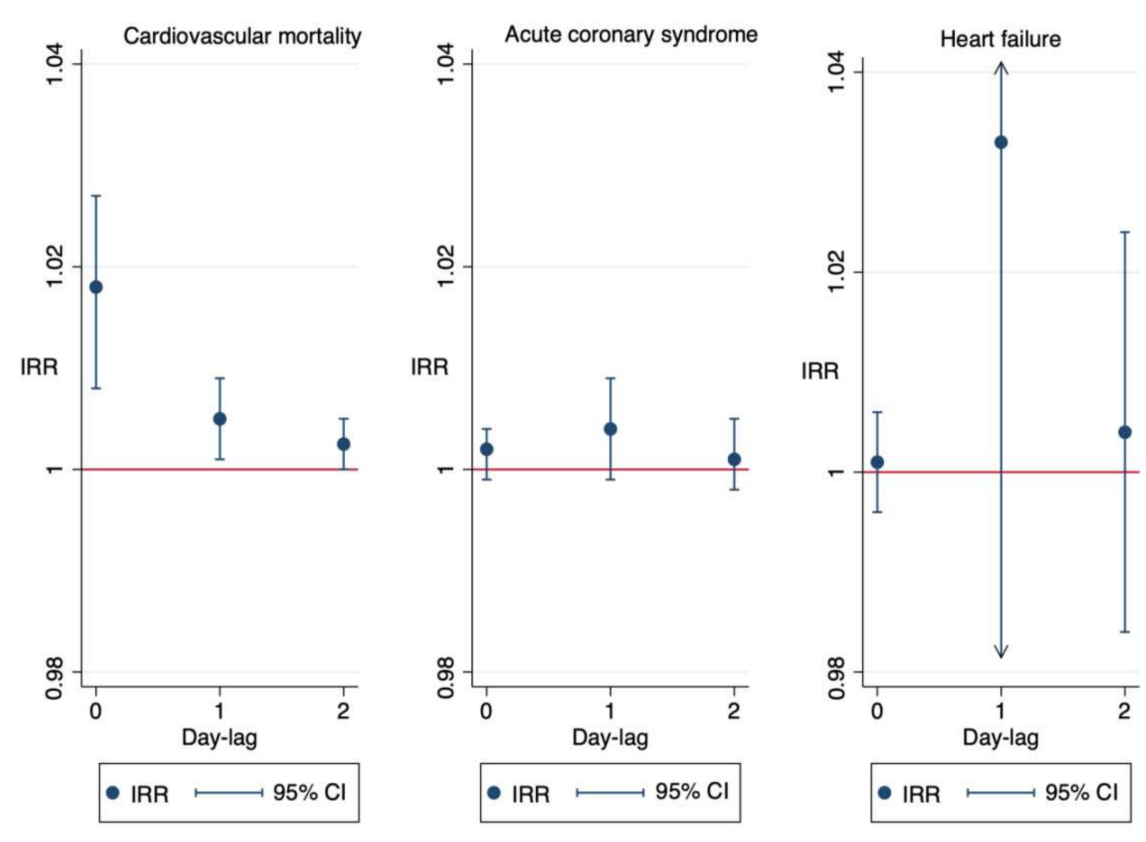

Figure 4. Meta-analyses performed for each objective and for each lag day from the day of exposure to desert dust until a lag of 2 days (lag 0 , lag 1, and lag 2).

\subsection{Heart Failure}

Of the selected studies, four provided information on the impact of $\mathrm{PM}_{10}$-dust on the incidence of admissions due to heart failure [25,29,30,33], comprising a total of 84,192 events. For lag 0 in relation to heart failure, the impact of PM10-dust was IRR $=1.001$ (95\% CI $0.996-1.006) ; p=0.67 ; \mathrm{I}^{2}=0 \%$. The Begg and Egger tests yielded $p=0.73$ and $p=0.94$, respectively. For lag 1 in relation to heart failure, the impact of $\mathrm{PM}_{10}$-dust was IRR $=1.033$ (95\% CI 0.977-1.091); $p=0.253 ; \mathrm{I}^{2}=0 \%$. The Begg and Egger tests yielded $p=0.29$ and $p=0.06$, respectively. For lag 2 in relation to heart failure, the impact of $\mathrm{PM}_{10}$-dust was $\mathrm{IRR}=1.004$ (95\% CI 0.984-1.024); $p=0.698 ; \mathrm{I}^{2}=0 \%$. The Begg and Egger tests yielded $p=0.30$ and $p=0.71$, respectively (Table 2). Fewer than three studies contributed information on the influence of $\mathrm{PM}_{10}$-dust in relation to lag 3, lag 4, lag 5, lag 0-1, lag 0-5, and lag $2-5$. Therefore, no weighted means were calculated for these days.

\section{Discussion}

Based on studies of time series and cross-case designs with strict inclusion criteria and almost 700,000 events, the present meta-analysis provides strong evidence of an association between desert dust and cardiovascular mortality. This association was seen to be stronger on the same day of exposure to dust and weaker over the following days. 
To the best of our knowledge, this is the first meta-analysis on the effect of desert dust on cardiovascular events.

Our results are of utmost importance. Every year, especially in summer, Saharan dust travels across the Atlantic and reaches several parts of the world. In June 2020, a tremendous plume of dust from North Africa was detected approaching the USA and other countries (Figure 5 and Supplementary Materials Video S1). The intensity and extent of the plume was so great that it blanketed the Caribbean Sea and darkened skies in several states in the USA [34].

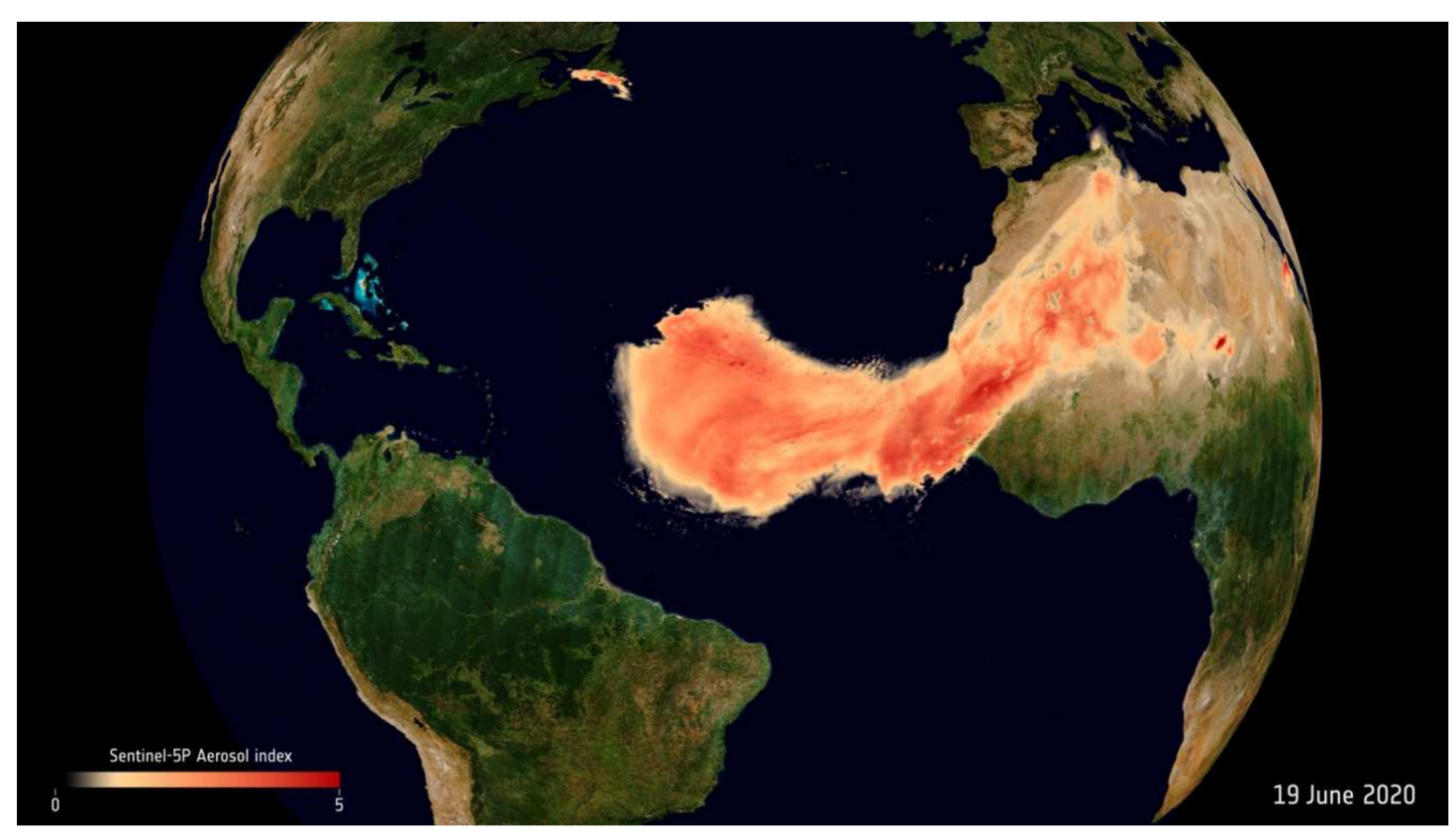

Figure 5. Data from the Copernicus Sentinel satellites and ESA's Aeolus satellite show the extent of this year's summer dust plume, dubbed "Godzilla," on its journey across the Atlantic.

Different studies conducted individually in different regions have evaluated the relationship between desert dust and ACS $[14,24,25,28-32]$ and heart failure $[25,29,30,33]$. In our opinion, the number of studies made is clearly insufficient to be able to draw conclusions. Moreover, many of the studies have been carried out in regions where local and regional pollution contributes far more than desert dust to the $\mathrm{PM}_{10}$ levels, i.e., $\mathrm{PM}_{10^{-}}$ pollution-combustion $>\mathrm{PM}_{10}$-dust.

Table 1 shows the $\mathrm{PM}_{10}$ values during the dust and non-dust episodes $\left(\mathrm{PM}_{10}\right.$ of component dominated by local and regional pollution) in each study. It also shows the $\mathrm{PM}_{10}$ during dust episodes and $\mathrm{PM}_{10}$ non-dust episodes ratio as a measure of the "increase" in $\mathrm{PM}_{10}$ during the desert dust events. It can be seen that the studies carried out in southern Europe (Greece, Italy, and continental Spain) and Turkey reflect a truly modest increment of between 1.0-1.4, i.e., $\mathrm{PM}_{10}$ did not increase significantly during the desert dust episodes, since the mean increment was 37 to $48 \mu \mathrm{g} / \mathrm{m}^{3}$. In Brescia (northern Italy), the $\mathrm{PM}_{10}$ even decreased during the desert dust events $\left(42\right.$ to $38 \mu \mathrm{g} / \mathrm{m}^{3}$ ). These study zones are shown in Figure 6 (red circle).

In the study carried out in Barcelona (Spain), $\mathrm{PM}_{10}$ reached $\sim 39 \mu \mathrm{g} / \mathrm{m}^{3}$ during the Saharan episodes, of which only $16 \mu \mathrm{g} / \mathrm{m}^{3}$ corresponded to desert dust—a load similar to that recorded in other zones of southern Europe [23]. In addition, the climatic conditions under which these desert dust events take place often favor the accumulation of local [35] and regional pollutants (thermal inversions secondary to hot air advection at high altitude) $[36,37]$, which can also contribute to the adverse effects on health. 


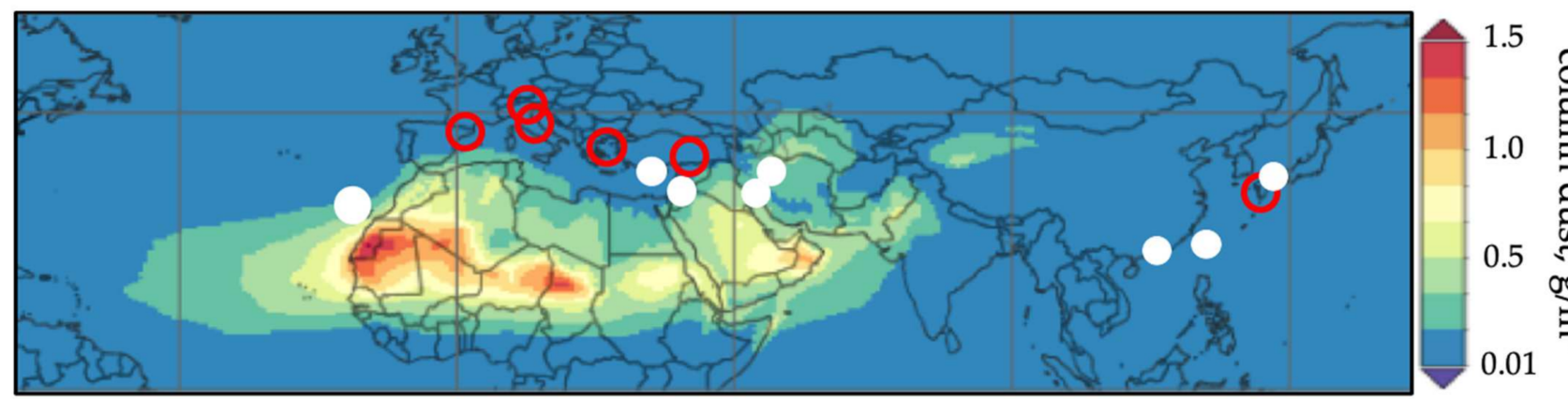

Figure 6. Distribution of the regions in which the studies on dust and cardiovascular disorders have been carried out based on the systematic review. Note the regions (white dot) in which the $\mathrm{PM}_{10}$ levels during the dust episodes are high, i.e., two or more times higher than those recorded in the absence of desert dust (from west to east): Tenerife-Spain, Nicosia-Cyprus, BéerSheva-Israel, Ahvaz-Iran, Teheran-Iran, Hong Kong-China, Taipei-Taiwan, and FukuokaJapan. Note the regions (red circle) in which the $\mathrm{PM}_{10}$ levels during the dust episodes do not increase significantly, i.e., without reaching two times those recorded in the absence of desert dust (from west to east): Barcelona-Spain, Brescia-Italy, Emilia Romagna-Italy, Athens-Greece, Gaziantep-Turkey, and western Japan. Column dust is shown according to MERRA-2 model.

In contrast, in the studies carried out in Asia (Japan, Taiwan and China), the Middle East (Iran and Israel), northern Africa (Tenerife), and Cyprus, the $\mathrm{PM}_{10}$ values experienced an important increase during the dust episodes, with a $\mathrm{PM}_{10}$ during dust episodes and $\mathrm{PM}_{10}$ non-dust episodes ratio of between 2-53, and $\mathrm{PM}_{10}$ increments from $54 \mu \mathrm{g} / \mathrm{m}^{3}$ to $157 \mu \mathrm{g} / \mathrm{m}^{3}$ on average $\left(2650 \mu \mathrm{g} / \mathrm{m}^{3}\right.$ in Israel). These studies were made in the so-called Dust Belt (Figure 6, white dot). In our opinion, these are the regions where further research is needed. With regard to the studies addressing heart failure and ACS, only two $[25,33]$ (out of a total of four) and three $[14,24,28]$ (out of a total of five) were carried out in that region, respectively.

Desert dust has a significant impact on air quality not only in areas close to the source points or regions, but also over areas up to a few thousand kilometers away [4].

\section{Limitations}

Some limitations of our analysis need to be acknowledged. First, we found a moderate degree of inconsistency. Due to the paucity of studies available, we could not perform subgroup analysis or meta-regression that could shed light in the presence of inconsistency. Second, we reported the estimated effect as IRR. Data extraction of the different studies included the estimated effect based on the odds ratio, relative risks, and IRR. The measurements of the odds ratio and relative risks would be almost equivalent when risks are very low [38]. Third, although this meta-analysis was conceived to increase statistical power and improve precision, we cannot rule out a lack of statistical power, especially in some endpoints with few involved studies or others with some degree of inconsistency. Fourth, the effects of desert dust on health depend on the trajectory and distance between the desert dust storms and the human populations [8]. Finally, the studies included in the present meta-analysis may have been influenced by geographical bias, since $67 \%$ of them were made outside the Dust Belt — a fact that may condition the absence of statistical significance referred to cardiovascular events in the form of ACS and heart failure. Caution should therefore be exercised when interpreting the pooled risk estimates and highlights the need for more data to increase the certainty of these risk estimates [39].

\section{Conclusions}

This is the first meta-analysis that has demonstrated that exposure to desert dust results in a $2 \%$ increase (for every $10 \mu \mathrm{g} / \mathrm{m}^{3}$ of $\mathrm{PM}_{10}$-dust) in cardiovascular mortality risk as assessed on the same day of exposure. Desert dust also increases the cardiovascular mortality risk as assessed 1 and 2 days after exposure, though, in this case, the effect is less 
important. The results of this study may help to alert the most vulnerable populations to adopt adequate measures during desert dust episodes.

Supplementary Materials: The following are available online at https:/ /www.mdpi.com/2077-038 3/10/4/727/s1, Figure S1: Search strategies, Video S1: Supplementary video.

Author Contributions: A.D.-R. had full access to all of the data in the study and takes responsibility for the integrity of the data and the accuracy of the data analysis. Concept and design: A.D.-R., N.B.-F. and P.A.-G.; Acquisition, analysis, or interpretation of data: A.D.-R., N.B.-F., P.A.-G., S.R., R.D., P.A., and D.H.-V.; Drafting of the manuscript: A.D.-R. and D.H.-V.; Critical revision of the manuscript for important intellectual content: S.R. and P.A.; Statistical analysis: D.H.-V.; Obtained funding: A.D.-R. and S.R.; Administrative, technical, or material support: A.D.-R., N.B.-F., P.A.-G., S.R., R.D., P.A. and D.H.-V.; Supervision: A.D.-R., P.A.-G., S.R. and D.H.-V. All authors have read and agreed to the published version of the manuscript.

Funding: This study was made within the setting of project VARDUST-SAL (PGC2018-099166-BI00), funded by the Spanish State Research Agency (Agencia Estatal de Investigación), the Spanish Ministry of Science, Innovation and University (Ministerio de Ciencia, Innovación y Universidad), and the European Regional Development Fund.

Institutional Review Board Statement: Not applicable.

Informed Consent Statement: Not applicable.

Data Availability Statement: Not applicable.

Acknowledgments: Some of the analyses and visualizations used in this study were produced with the Giovanni online data system, developed and maintained by the NASA GES DISC.

Conflicts of Interest: The authors declare no conflict of interest.

\section{References}

1. Ambient Air Pollution: A Global Assessment of Exposure and Burden of Disease. 2016. Available online: https://www.who.int/ phe/publications/air-pollution-global-assessment/en/ (accessed on 17 May 2020).

2. Landrigan, P.J.; Fuller, R.; Acosta, N.J.R.; Adeyi, O.; Arnold, R.; Basu, N.; Baldé, A.B.; Bertollini, R.; Bose-O'Reilly, S.; Boufford, J.I.; et al. The Lancet Commission on pollution and health. Lancet 2018, 391, 462-512. [CrossRef]

3. Kotsyfakis, M.; Zarogiannis, S.G.; Patelarou, E. The health impact of Saharan dust exposure. Int. J. Occup. Med. Environ. Health 2019, 32, 749-760. [CrossRef]

4. Prospero, J.M.; Ginoux, P.; Torres, O.; Nicholson, S.E.; Gill, T.E. Environmental characterization of global sources of atmospheric soil dust identified with the Nimbus 7 Total Ozone Mapping Spectrometer (TOMS) absorbing aerosol product. Rev. Geophys. 2002, 40, 1-31. [CrossRef]

5. Escudero, M.; Querol, X.; Pey, J.; Alastuey, A.; Pérez, N.; Ferreira, F.; Alonso, S.; Rodríguez, S.; Cuevas, E. A methodology for the quantification of the net African dust load in air quality monitoring networks. Atmos. Environ. 2007, 41, 5516-5524. [CrossRef]

6. Rodriguez, S.; Querol, X.; Alastuey, A.; Viana, M.M.; Alarcon, M.; Mantilla, E.; Ruiz, C.R. Comparative $\mathrm{PM}_{10}-\mathrm{PM}_{2.5}$ source contribution study at rural, urban and industrial sites during PM episodes in Eastern Spain. Sci. Total Environ. 2004, 328, 95-113. [CrossRef]

7. Stafoggia, M.; Zauli-Sajani, S.; Pey, J.; Samoli, E.; Alessandrini, E.; Basagaña, X.; Cernigliaro, A.; Chiusolo, M.; Demaria, M.; Díaz, J.; et al. Desert dust outbreaks in southern Europe: Contribution to daily $\mathrm{PM}_{10}$ concentrations and short-term associations with mortality and hospital admissions. Environ. Health Perspect. 2016, 124, 413-419. [CrossRef] [PubMed]

8. Querol, X.; Tobías, A.; Pérez, N.; Karanasiou, A.; Amato, F.; Stafoggia, M.; García-Pando, C.P.; Ginoux, P.; Forastiere, F.; Gumy, S.; et al. Monitoring the impact of desert dust outbreaks for air quality for health studies. Environ. Int. 2019, 130, 104867. [CrossRef]

9. Marticorena, B.; Chatenet, B.; Rajot, J.L.; Bergametti, G.; Deroubaix, A.; Vincent, J.; Kouoi, A.; Schmechtig, C.; Coulibaly, M.; Diallo, A.; et al. Mineral dust over west and central Sahel: Seasonal patterns of dry and wet deposition fluxes from a pluriannual sampling (2006-2012). J. Geophys. Res. Atmos. 2017, 122, 1338-1364. [CrossRef]

10. Karanasiou, A.; Moreno, N.; Moreno, T.; Viana, M.; de Leeuw, F.; Querol, X. Health effects from Sahara dust episodes in Europe: Literature review and research gaps. Environ. Int. 2012, 47, 107-114. [CrossRef] [PubMed]

11. de Longueville, F.; Ozer, P.; Doumbia, S.; Henry, S. Desert dust impacts on human health: An alarming worldwide reality and a need for studies in West Africa. Int. J. Biometeorol. 2013, 57, 1-19. [CrossRef]

12. Zhang, X.; Zhao, L.; Tong, D.; Wu, G.; Dan, W.; Teng, B. A systematic review of global desert dust and associated human health effects. Atmosphere 2016, 7, 158. [CrossRef]

13. Winquist, A.; Klein, M.; Tolbert, P.; Sarnat, S.E. Power estimation using simulations for air pollution time-series studies. Environ. Health 2012, 11, 68. [CrossRef] [PubMed] 
14. Domínguez-Rodríguez, A.; Rodríguez, S.; Baez-Ferrer, N.; Avanzas, P.; Abreu-González, P.; Silva, J.; Morís, C.; Hernández-Vaquero, D. Impact of Saharan dust on the incidence of acute coronary syndrome. Rev. Esp. Cardiol. 2020, in press. [CrossRef]

15. Moher, D.; Liberati, A.; Tetzlaff, J.; Altman, D.G.; PRISMA Group. Preferred reporting items for systematic reviews and meta-analyses: The PRISMA statement. BMJ 2009, 339, b2535. [CrossRef] [PubMed]

16. Ambient (Outdoor) Air Pollution. 2018. Available online: https://www.who.int/news-room/fact-sheets/detail/ambient(outdoor)-air-quality-and-health (accessed on 17 May 2020).

17. Lu, Y.; Zeger, S.L. On the equivalence of case-crossover and time series methods in environmental epidemiology. Biostatistics 2007, 8, 337-344. [CrossRef] [PubMed]

18. Sterne, J.A.; Hernán, M.A.; Reeves, B.C.; Savović, J.; Berkman, N.D.; Viswanathan, M.; Henry, D.; Altman, D.G.; Ansari, M.T.; Boutron, I.; et al. ROBINS-I: A tool for assessing risk of bias in non-randomized studies of interventions. BMJ 2016, 355 , i4919. [CrossRef]

19. Higgins, J.P.; Thompson, S.G.; Deeks, J.J.; Altman, D.G. Measuring inconsistency in meta-analyses. BMJ 2003, 327, 557-560. [CrossRef] [PubMed]

20. Sajani, S.Z.; Miglio, R.; Bonasoni, P.; Cristofanelli, P.; Marinoni, A.; Sartini, C.; Goldoni, C.A.; De Girolamo, G.; Lauriola, P. Saharan dust and daily mortality in Emilia-Romagna (Italy). Occup. Environ. Med. 2011, 68, 446-451. [CrossRef]

21. Samoli, E.; Kougea, E.; Kassomenos, P.; Analitis, A.; Katsouyanni, K. Does the presence of desert dust modify the effect of PM10 on mortality in Athens, Greece? Sci. Total Environ. 2011, 409, 2049-2054. [CrossRef]

22. Mallone, S.; Stafoggia, M.; Faustini, A.; Gobbi, G.P.; Marconi, A.; Forastiere, F. Saharan dust and associations between particulate matter and daily mortality in Rome, Italy. Environ. Health Perspect. 2011, 119, 1409-1414. [CrossRef]

23. Pérez, L.; Tobías, A.; Pey, J.; Pérez, N.; Alastuey, A.; Sunyer, J.; Querol, X. Effects of local and Saharan particles on cardiovascular disease mortality. Epidemiology 2012, 23, 768-769. [CrossRef]

24. Kashima, S.; Yorifuji, T.; Tsuda, T.; Eboshida, A. Asian dust and daily all-cause or cause-specific mortality in western Japan. Occup. Environ. Med. 2012, 69, 908-915. [CrossRef]

25. Tam, W.W.; Wong, T.W.; Wong, A.H. Effect of dust storm events on daily emergency admissions for cardiovascular diseases. Circ. J. 2012, 76, 655-660. [CrossRef] [PubMed]

26. Neophytou, A.M.; Yiallouros, P.; Coull, B.A.; Kleanthous, S.; Pavlou, P.; Pashiardis, S.; Dockery, D.W.; Koutrakis, P.; Laden, F. Particulate matter concentrations during desert dust outbreaks and daily mortality in Nicosia, Cyprus. J. Expo. Sci. Environ. Epidemiol. 2013, 23, 275-280. [CrossRef] [PubMed]

27. Shahsavani, A.; Tobías, A.; Querol, X.; Stafoggia, M.; Abdolshahnejad, M.; Mayvaneh, F.; Guo, Y.; Hadei, M.; Hashemi, S.S.; Khosravi, A.; et al. Short-term effects of particulate matter during desert and non-desert dust days on mortality in Iran. Environ. Int. 2020, 134, 105299. [CrossRef] [PubMed]

28. Vodonos, A.; Friger, M.; Katra, I.; Krasnov, H.; Zahger, D.; Schwartz, J.; Novack, V. Individual Effect Modifiers of Dust Exposure Effect on Cardiovascular Morbidity. PLoS ONE 2015, 10, e0137714. [CrossRef] [PubMed]

29. Vaduganathan, M.; De Palma, G.; Manerba, A.; Goldoni, M.; Triggiani, M.; Apostoli, P.; Dei Cas, L.; Nodari, S. Risk of Cardiovascular Hospitalizations from Exposure to Coarse Particulate Matter (PM10) Below the European Union Safety Threshold. Am. J. Cardiol. 2016, 117, 1231-1235. [CrossRef]

30. Al, B.; Bogan, M.; Zengin, S.; Sabak, M.; Kul, S.; Oktay, M.M.; Bayram, H.; Vuruskan, E. Effects of Dust Storms and Climatological Factors on Mortality and Morbidity of Cardiovascular Diseases Admitted to ED. Emerg. Med. Int. 2018, 2018, 3758506. [CrossRef]

31. Zhang, Q.; Qi, W.; Yao, W.; Wang, M.; Chen, Y.; Zhou, Y. Ambient Particulate Matter (PM(2.5)/PM(10)) Exposure and Emergency Department Visits for Acute Myocardial Infarction in Chaoyang District, Beijing, China During 2014: A Case-Crossover Study. J. Epidemiol. 2016, 26, 538-545. [CrossRef]

32. Matsukawa, R.; Michikawa, T.; Ueda, K.; Nitta, H.; Kawasaki, T.; Tashiro, H.; Mohri, M.; Yamamoto, Y. Desert dust is a risk factor for the incidence of acute myocardial infarction in Western Japan. Circ. Cardiovasc. Qual. Outcomes 2014, 7, 743-748. [CrossRef]

33. Yang, C.Y.; Cheng, M.H.; Chen, C.C. Effects of Asian dust storm events on hospital admissions for congestive heart failure in Taipei, Taiwan. J. Toxicol. Environ. Health A 2009, 72, 324-328. [CrossRef]

34. NASA Earth Observatory, USA. Available online: https://earthobservatory.nasa.gov/images/146913/a-dust-plume-toremember (accessed on 27 June 2020).

35. Rius, J.B.; Ferreira-González, I.; Marsal, J.R.; Barrabés, J.A.; Ribera, A.; Lidón, R.M.; Domingo, E.; Martí, G.; García-Dorado, D. Short-term exposure to air pollutants increases the risk of ST elevation myocardial infarction and of infarct-related ventricular arrhythmias and mortality. Int. J. Cardiol. 2018, 250, 35-42.

36. Milford, C.; Cuevas, E.; Marrero, C.L.; Bustos, J.J.; Gallo, V.; Rodríguez, S.; Romero-Campos, P.M.; Torres, C. Impacts of desert dust outbreaks on air quality in urban areas. Atmosphere 2020, 11, 23. [CrossRef]

37. Pandolfi, M.; Tobías, A.; Alastuey, A.; Sunyer, J.; Schwartz, J.; Lorente, J.; Pey, J.; Querol, X. Effect of atmospheric mixing layer depth variations on urban air quality and daily mortality during Saharan dust outbreaks. Sci. Total Environ. 2014, 494-495, 283-289. [CrossRef] [PubMed]

38. Gao, H.; Wang, K.; Au, W.W.; Zhao, W.; Xia, Z. A Systematic Review and Meta-Analysis of Short-Term Ambient Ozone Exposure and COPD Hospitalizations. Int. J. Environ. Res. Public Health 2020, 17, 2130. [CrossRef] [PubMed]

39. Navarese, E.P.; Buffon, A.; De Luca, G.; De Servi, S. Regarding "a closer look at meta-analyses of observational data". J. Vasc. Surg. 2010, 52, 819. [CrossRef] [PubMed] 